www.jmscr.igmpublication.org

Impact Factor 5.84

Index Copernicus Value: 83.27

ISSN (e)-2347-176x ISSN (p) 2455-0450

crossref DOI: _https://dx.doi.org/10.18535/jmscr/v5i4.200

Journal Of Medical Science And Clinical Research

\title{
The Potential Role of Apparent Diffusion Coefficient Values In the Differentiation of Infective and Tuberculous Lymph Nodes of Neck - In Correlation with Histopathology
}

\author{
Authors \\ Dr Praveen Sharma MD, Dr Rujuta Narendra Rege MD², Dr Adipudi Renuka $\mathrm{MD}^{3}$ \\ Dr Avinash Naikwadi DNB ${ }^{4}$, Prof. Dr Kulasekaran DMRD MD ${ }^{5}$ \\ Dr C.R. Seena MD DNB ${ }^{6}$ \\ ${ }^{1}$ Assistant Professor, Saveetha Medical College and Hospital, ${ }^{2}$ Saveetha Medical College and Hospital \\ ${ }^{3} 1^{\text {st }}$ Year Post Graduate, Saveetha Medical College and Hospital, ${ }^{4}$ Nanavathi Hospital, Mumbai \\ ${ }^{5}$ Professor and Head of Department, Saveetha Medical College and Hospital \\ ${ }^{6}$ Professor, Saveetha Medical College and Hospital \\ Corresponding Author
}

Dr Praveen Sharma MD

Assistant Professor, Saveetha Medical College and Hospital

\begin{abstract}
Study was done in 40 patients to ascertain the different causes of cervical lymphadenopathy. 13 patients with cervical lymph node metastasis from infective etiology and 27 patients with tuberculous lymphadenitis underwent conventional magnetic resonance imaging (MRI) and diffusion-weighted imaging (DWI). The ADC values of necrotic and solid portions of lymph nodes were measured and compared. Receiver operating characteristic (ROC) analysis was employed to investigate whether ADC values could help to distinguish between the causes of cervical lymphadenopathy.

Aims: To assess the role of MRI with the help of DWI and ADC to differentiate infectivefrom tuberculous lymph nodes.

Objective: To calculate statistical parameters in the differentiation of infective and tuberculous lymph nodes of neck using diffusion weighted imaging (DWI) and apparent diffusion coefficient (ADC) values with histopathological examination as the gold standard.

Methods and Material

Inclusion Criteria

- Patients presenting with cervical lymphadenopathy detected either clinically or by other radiological investigations. In case of multiple lymph nodes, largest will be included in the study.

- Patients who undergo biopsy for the same.

Exclusion Criteria

- $\quad$ Patients with cervical lymph node of size less than $15 \mathrm{~mm}$ in short axis on USG

- Painful lymph nodes.

- Patients with contraindications for MR examination.

- $\quad$ Patients not willing to participate in the study

Results: In our study we found that the range of ADC values for tuberculous cervical lymph nodes was between $0.99-1.01 \times 10$ $3 \mathrm{~mm} 2 / \mathrm{s}$ in the solid portion of the lymph node and $1.27-1.31 \times 10-3 \mathrm{~mm} 2 / \mathrm{s}$ in the necrotic portion of the lymph node. The mean of $A D C$ values for infective cervical lymph nodes was between $1.0-1.2 \times 10-3 \mathrm{~mm} 2 / \mathrm{s}$ in the solid portion and in the necrotic portion the values - NIL. The „p" value was <0.001, this showed that there is good agreement between the ADC values and the histopathology results.

Conclusions: The ADC values both of the necrotic and solid portions of the lymph nodes are useful in differentiation between the causes of cervical lymphadenopathy. The ADC value of necrosis is especially helpful in discriminating infective from tuberculosis.

Key-words: DWI, ADC value, solid and necrotic portion of lymph nodes.
\end{abstract}




\section{INTRODUCTION}

Modern imaging modalities such as ultrasound, computed tomography and magnetic resonance imaging allow reliable detection of cervical lymph nodes. However, the differentiation of benign and malignant lymph nodes remains very challenging. In addition to a size of more than $10 \mathrm{mms}$, morphological criteria such as rounded shape, regional grouping of lymph nodes, and presence of necrosis, extra capsular tumor spread or the invasion of adjacent structures are indicative of malignancy. Unfortunately, none of these criteria is absolutely reliable. Several reports showed that these parameters are not enough to discriminate benign from malignant lymph nodes. The size is certainly the most used criterion for the diagnosis, whereas the presence ofcentral necrosis is the most reliable criterion of malignancy. Lymph nodes maybe enlarged reactively and even small lymph nodes may be infiltrated by malignant cells. Presence of necrosis is the strongest indicator for malignanacy, but necrosis has been shown to occur in benign conditions as well. ${ }^{[1-6]}$

Alternative imaging modalities such as single photon emission computed tomography (SPECT) and positron emission tomography (PET) can help to differentiate between benign and malignant lymph nodes. However, these methods are invasive, expensive, time consuming and hampered by limited spatial resolution. ${ }^{[7]}$

Ultrasound guided fine needle aspiration cytology (USgFNAC) is a valuable tool in characterizing cervical lymph nodes, but the method is invasive and operator dependent. ${ }^{[8]}$

Whereas conventional MR sequences do not seem to be superior to CT. Nowadays the newer MRI technique of diffusion weighted imaging (DWI) and apparent diffusion coefficient mapping [ADC mapping ], is used which is a non-invasive MRI technique. It is based on intravoxel incoherent motions imaging and allows visualization of diffusion properties of water molecules in biologic tissues. It provides image contrast dependent on the molecular motions of water. Any architectural changes in the proportion of intracellular and extracellular water protons will alter the diffusion coefficient of the tissue. Therefore, DWI would help in characterization of different tissues and lesions. ${ }^{[9,10]}$

\section{ANATOMY}

\section{Surgical classification of cervical lymph nodes}

The most recent American Head and Neck Society (AHNS) and American Academy of Otolaryngology-Head and Neck Surgery have developed a widely accepted division of cervical lymph nodes into 7 numbered nodal levels with well defined anatomic boundaries that can be easily identified by both surgeons and radiologists. (Table 1). ${ }^{[15-22]}$

Table 1: The cervical lymph nodes levels

\begin{tabular}{|l|c|c|}
\hline Levels & Sublevels & Nodes \\
\hline Level I & I A & Submental nodes \\
\hline & I B & Submandibular nodes \\
\hline Level II & II A & Antero-inferior upper jugular nodes \\
\hline & II B & Postero-superior upper jugular nodes \\
\hline Level III & & Middle jugular nodes \\
\hline Level IV & & Lower jugular nodes \\
\hline Level V & V A & Superior posterior neck nodes \\
\hline & V B & Inferior posterior neck nodes \\
\hline Level VI & & Central (anterior) nodes \\
\hline Level VII & & Superior mediastinal nodes \\
\hline
\end{tabular}

\section{Magnetic Resonance Imaging (MRI)}

MRI is a modality with no hazard from ionizing radiation and it with its high contrast resolution and multi planar imaging capabilities readily detects abnormal lymph nodes and modern turbospin echo sequences have helped shorten the examination time. MRI has added value in evaluating a primary neoplastic process, with improved detection of bone marrow involvement and perineural spread of disease. The role of contrast-enhanced imaging in MRI is well established. Gadolinium contrast media is integral to the evaluation of cervical lymph nodes by MRI in evaluating for nodal necrosis and in evaluating characteristics of the primary lesion such as perineural spread of malignancy. Perfusion techniques evaluate dynamic microscopic blood flow changes by documenting changes in signal intensity in a given region of interest after bolus administration of contrast material. These techniques are non-invasive and can be obtained 
without adding significant additional time to imaging protocols. Recent studies of dynamic susceptibility weighted perfusion MRI have shown promise in differentiating metastasis from benign lymph nodes. ${ }^{[23,24,33]}$

\section{Diffusion weighted imaging (DWI) Restricted diffusion}

DWI is a non-invasive imaging technique, which probes the physical structure of a biologic tissue. DWI reveals insight into the morphologic composition of a tissue well below the typical millimeter-scale resolution of other imaging techniques. DWI exploits the random motions of water in the targeted tissue which reflects the tissue specific diffusion capacity. Thus the diffusion capacity can be used for tissue characterization. ${ }^{[25-30]}$ In water free diffusivity is present and water molecules show unrestricted diffusion. In biologic tissues the diffusivity of water molecules is confined by the intracellular and extracellular spaces. Rapidly growing malignant tumors are composed of layers of densely packed tumor cells with high energy turnover. These tumor cells present with enlarged nuclei, increased numbers of intracellular organelles and reduced cytoplasm. As a consequence the dimensions of both the intracellular and the extracellular spaces are reduced, resulting in decreased mobility of water protons and consequently a restricted diffusion capacity of the tissue. The signal on DWI derived from diffusion sensitized water protons which show translational motions along the applied diffusion gradient. In a tissue with restricted diffusion capacity such as in tumor tissues the mobility of diffusion sensitized water protons is decreased resulting in increased signals on DWI. Thus, tumors present with bright signals on DWI. ${ }^{[31,35-37]}$.

Benign tissues are in general composed of loosely attached cells with small nuclei and increased amounts of cytoplasm resulting in enlarged intracellular and extracellular spaces. In these tissues the diffusion capacity is not restricted and diffusion sensitized water protons show increased translational motions along the applied diffusion gradient. This motion results in a phase shift of the sensitized water protons and consecutively in a signal loss on DWI. ${ }^{[31,35,38]}$.

According to this concept the contrast on DWI reflects the different diffusion capacities of the tissues under investigation. Malignancies appear hyperintense on DWI whereas benign tissues and liquids appear hypointense. This concept of restricted diffusion in tumor tissues has been derived from theoretical and biological diffusion models and has been supported by results from animal studies and human trials. ${ }^{[31,32,36,37,28-41]}$.

\section{DWI and lymph nodes}

DWI is a well established imaging modality for the central nervous system (CNS). Its use for tissues outside the brain was limited for a long time because the image quality of non-CNS tissue was impaired by motion artifacts and challenging magnetic environment. Advances in the DWI software and in the hardware of MRI scanners improved image quality considerably and led to several reports describing the potential of DWI in the evaluation of non-CNS tissue. First reports described the power of DWI in the evaluation of bone marrow alterations in the spine. The contrast on DWI allowed the differentiation of benign from pathologic bone marrow alterations supporting the concept of restricted diffusion in tumor tissue. In the routine work-up of patients with compression fractures of vertebral bodies DWI provides reliable information to distinguish pathologic from osteoporotic fractures. Knowledge gained from these studies was used to solve the problems in distinguishing metastatic lymph nodes from reactive ones. First results were obtained from lymph nodes of the head and neck region using a navigated diffusion weighted echo planar imaging (DW-EPI) with $b$ factor values of $0 \mathrm{~s} / \mathrm{mm} 2$ and $800 \mathrm{~s} / \mathrm{mm} 2$. Regular lymph nodes showed ADC value of $1.21+/-0.24 \times 10-3 \mathrm{~mm} 2 / \mathrm{s}$ which was significantly higher than the diffusivity of metastatic lymph nodes (ADC value: $0.59+/-$ 
$0.27 \times 10-3 \mathrm{~mm} 2 / \mathrm{s})$. Similar results were published by other authors also ${ }^{[35-38]}$.

\section{b-factor value}

The term b-factor value refers to the strength of the diffusion sensitizing gradient which is proportional to the gradient amplitude, the duration of the applied gradient and the time interval between paired gradients. It is measured in seconds per square millimetre $(\mathrm{s} / \mathrm{mm} 2)$. The $\mathrm{b}$ factor value has to be determined by the specifications of the MR scanner and the image quality. As has been shown in previous studies which described the role of DWI in the evaluation of musculoskeletal (MSK) pathologies, a b-factor value of $800 \mathrm{~s} / \mathrm{mm} 2$ provides good image quality in respect to signal to noise ratio (SNR), acquisition time and spatial resolution. DWI obtained with lower b-values (less than 150 $\mathrm{s} / \mathrm{mm} 2$ ) will have higher SNR however, the ADC values may be falsified by signals from perfusion in small vessels, so called pseudo diffusion. Using higher b-factor values may improve the specificity of the contrast on DWI, however, lower signal SNR and increased susceptibility artifacts have to be traded in which will impair image quality and the accuracy of qualitative image analysis. There is no unique b-factor value established for DWI of lymph nodes yet. $b$-factor values are dependent on the hardware components of the scanner and the applied software used, which will be different for each site. Thus the appropriate $b$-factor value has to be evaluated for each scanner/coil system and the specific DW sequence used. (Figure 12 and 13). ${ }^{[33,38-40]}$
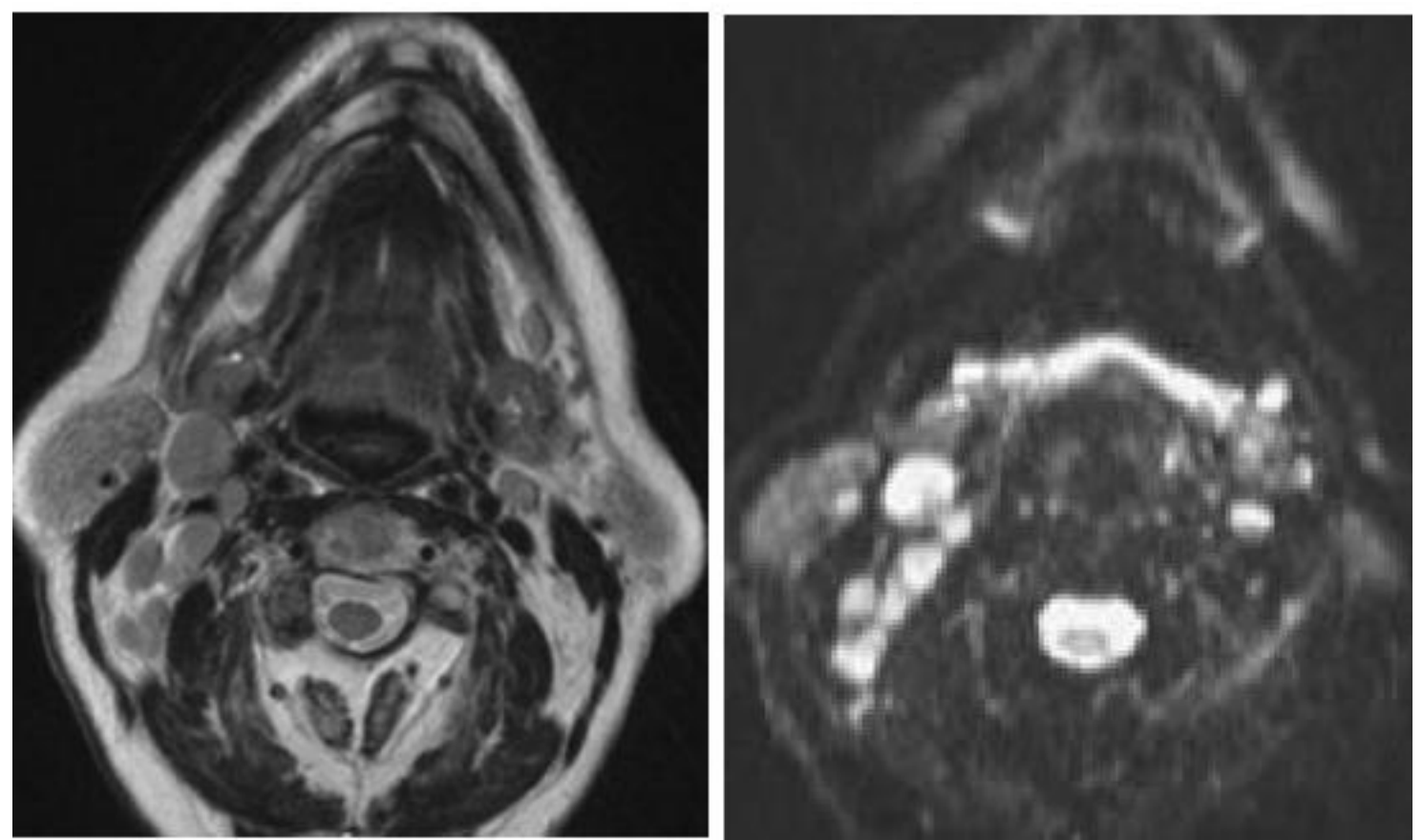

Figure 1: Metastatic cervical lymph nodes; First image: Axial fat suppressed T2 weighted MRI showing bilateral abnormal level II lymph nodes. Second image: Axial diffusion-weighted image obtained showing high signal intensities, showed $\mathrm{b}$ value $=0.79 \times 10^{-3} \mathrm{~s} / \mathrm{mm}^{2}$ seen in the solid portionin the lymph nodes. 


\section{JMSCR Vol||05||Issue||04||Page 21009-21021||April}
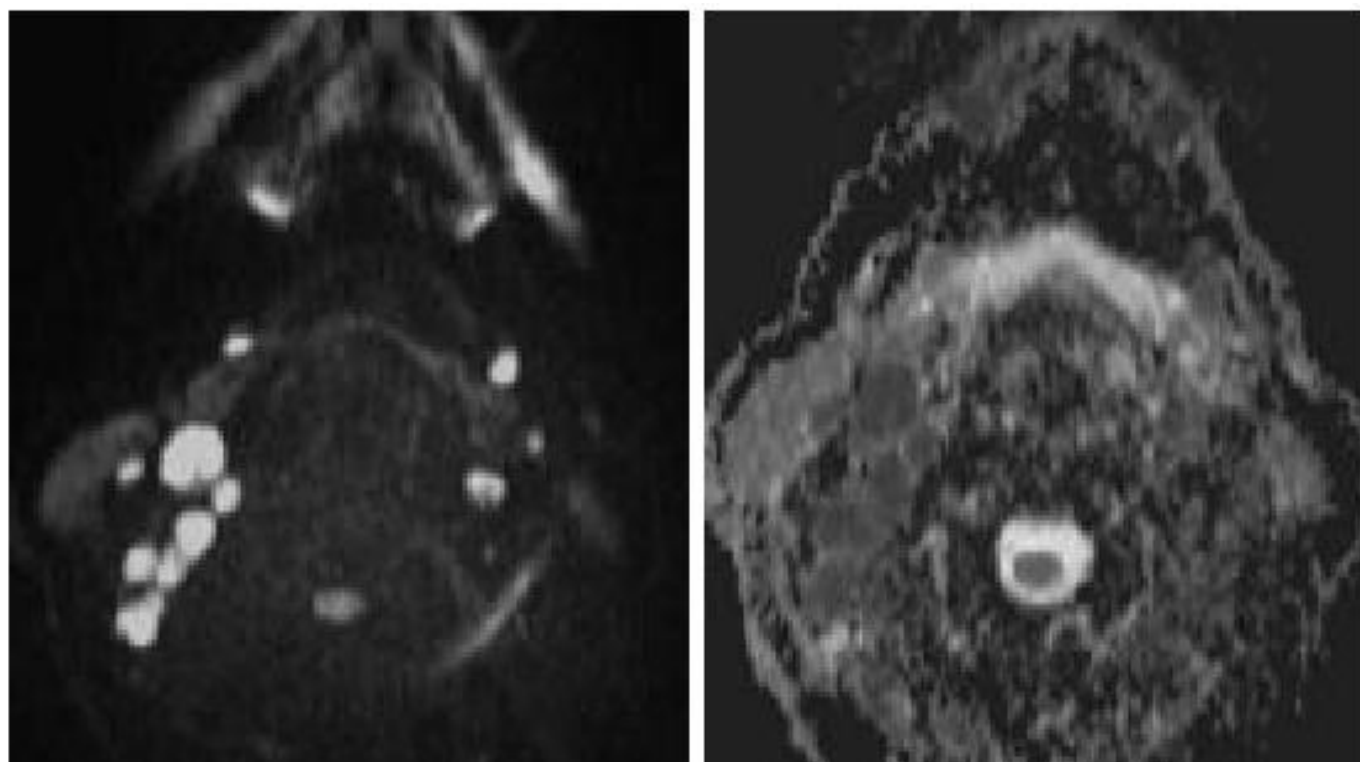

Figure 2: Metastatic cervical lymph nodes; First image: Axial diffusion-weighted image obtained showing high signal intensities, shows b value $=0.98 \times 10^{-3} \mathrm{~s} / \mathrm{mm} 2$ seen in the necrotic portion of the lymph node. ; Second image: Corresponding areas are hypointense on the ADC map.

\section{Histopathology}

It is the gold standard, and is considered the best for arriving at a particular diagnosis. Tissue diagnosis gives the most accurate results with a sensitivity and specificity of close to $100 \%$. Although it is an accurate method but is invasive and operator dependent with high incidence of false negative case. But it has shown importance in certain cases wherein there is overlapping of the disease like for example a patient having an underlying malignancy gets superimposed with tuberculous infection due to his immunecompromised status, where other imaging modalities have difficulty in differentiating the same.[Figure 14,15,16].

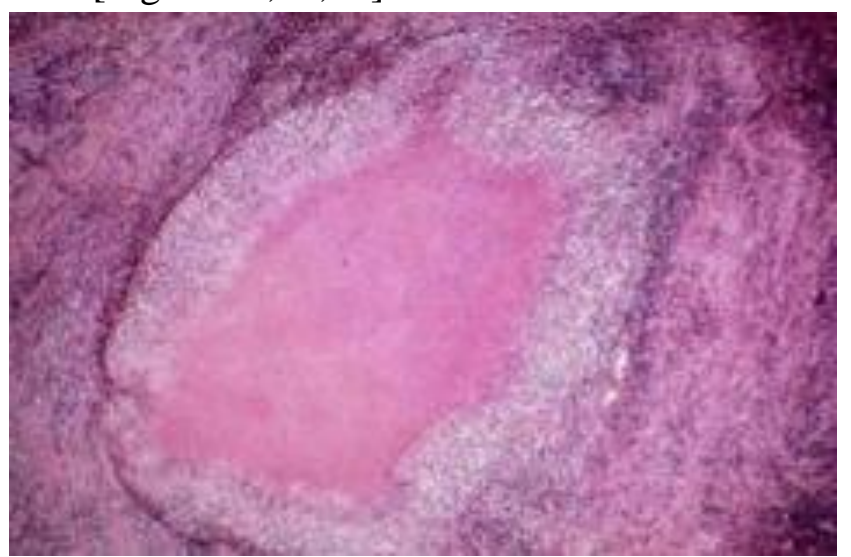

Figure 3:- Z-N stain for mycobacteria showed the presence of numerous granulomas characterized by central caseous necrosis, surrounded by a zone of epitheloid macrophages. There are scattered Langerhan's giant cells with multiple nuclei arranged in a peripheral pattern. The small round cells represent lymphocytes.

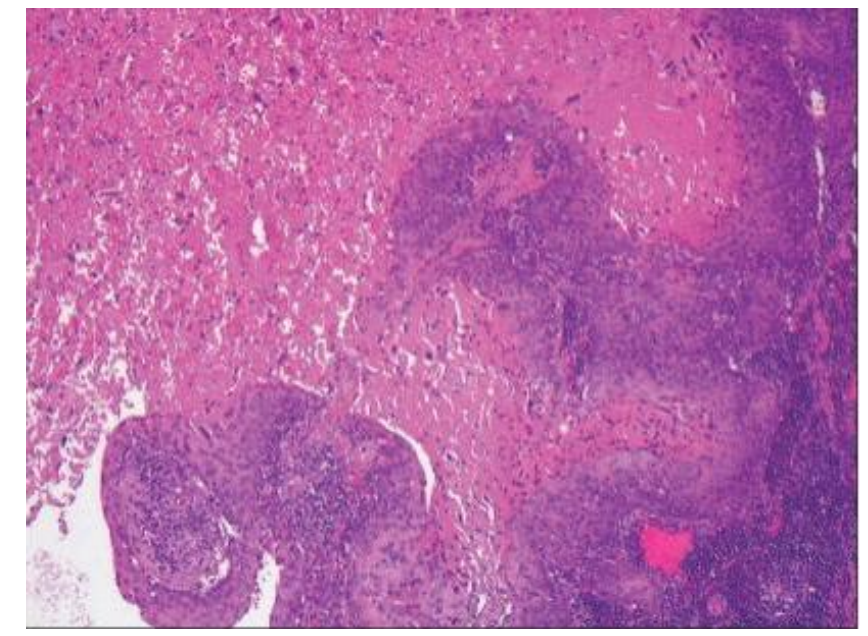

Figure 4:- Histopathology slide of metastatic squamous cell carcinoma to cervical lymph node with extensive tumor necrosis $(\mathrm{H}$ and $\mathrm{E}, \times 100)$ 


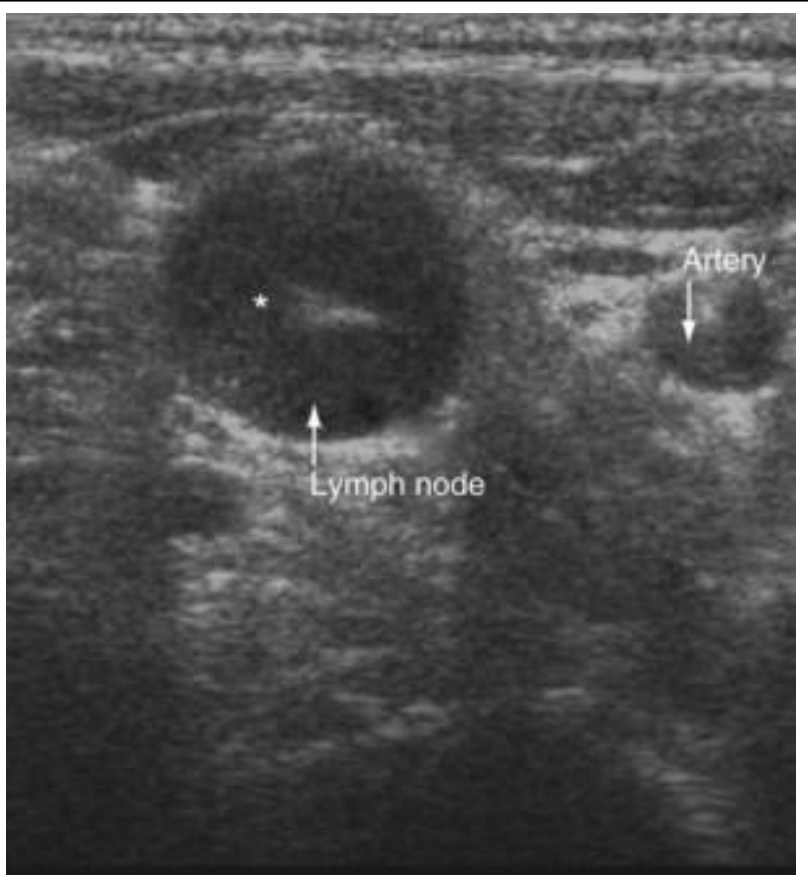

The present study "THE POTENTIAL ROLE OF APPARENT DIFFUSION COEFFICIENT VALUES IN THE DIFFERENTIATION OF INFECTIVE AND TUBERCULOUS LYMPH NODES OF NECK - IN CORRELATION WITH HISTOPATHOLOGY", was carried out from January 2015 to December 2015, in the department of Radiodiagnosis at our hospital which is a tertiary care centre in Southern parts of India. 40 patients having cervical lymphadenopathy were included in the study.

Figure 5: Neck ultrasound image showing an enlarged, rounded, hypoechoic lymph node characteristic of malignancy, undergoing fine needle aspiration with a 21-gauge needle (*indicates needle tip).

\section{OBSERVATIONS AND RESULTS}

Table 2: MRI Diagnosis with Histopathologic Correlation Cross tabulation Summary of MRI diagnosis V/S Histopathology diagnosis

\begin{tabular}{|c|c|c|c|c|c|}
\hline & & & Histopathc & gy Diagnosis & Total \\
\hline & & & $\begin{array}{l}\text { Infective } \\
\text { etiology }\end{array}$ & Tuberculous & \\
\hline $\begin{array}{l}\text { MRI } \\
\text { diagnosis }\end{array}$ & Infective etiology & $\begin{array}{l}\text { Count } \\
\% \text { withinHistopathologyDiagnosis } \\
\text { Histopathology Diagnosis }\end{array}$ & $\begin{array}{c}13 \\
100 \%\end{array}$ & $\begin{array}{c}0 \\
.0 \%\end{array}$ & $\begin{array}{c}13 \\
22.0 \%\end{array}$ \\
\hline & Tuberculous & $\begin{array}{l}\text { Count } \\
\% \text { withinHistopathologyDiagnosis } \\
\text { Histopathology Diagnosis }\end{array}$ & $\begin{array}{c}0 \\
.0 \%\end{array}$ & $\begin{array}{c}27 \\
100.0 \%\end{array}$ & $\begin{array}{c}27 \\
45.8 \%\end{array}$ \\
\hline & Total & $\begin{array}{l}\text { Count } \\
\% \text { withinHistopathologyDiagnosis } \\
\text { Histopathology Diagnosis }\end{array}$ & 13 & $\begin{array}{c}27 \\
100.0 \%\end{array}$ & $\begin{array}{c}40 \\
100.0 \%\end{array}$ \\
\hline
\end{tabular}

Table shows that amongst all the cases studied MRI gave a diagnosis of infectve etiology in 13 of the 13 cases which were given on histopathology which corresponded to $100 \%$. 27 patients were given a diagnosis of tuberculosis on MRI and histopathology, which showed $100 \%$ correlation.
Table 3:- Infective Lymph Nodes on MRI and Histopathology

\begin{tabular}{|l|c|c|}
\hline LN characteristic & $\begin{array}{c}\text { Infective on } \\
\text { MRI }\end{array}$ & $\begin{array}{c}\text { infective on } \\
\text { Histopathology }\end{array}$ \\
\hline LN with Necrosis & 0 & 0 \\
\hline LN without Necrosis & $13(100 \%)$ & $13(100 \%)$ \\
\hline Total & 13 & 13 \\
\hline
\end{tabular}




\section{JMSCR Vol||05||Issue||04||Page 21009-21021||April}

Amongst the patients studied MRI gave infective etiology in 13 patients whereas Histopathology gave infective etiology in 13 patients.

Table 4: MRI Diagnosis of Lymph node

\begin{tabular}{|l|c|c|}
\hline Diagnosis & Frequency & Percentage \\
\hline Infective & 13 & $32.5 \%$ \\
\hline Tuberculous & 27 & $67.5 \%$ \\
\hline Total & 40 & $100 \%$ \\
\hline
\end{tabular}

\section{Mri diagnosis of lymph node}

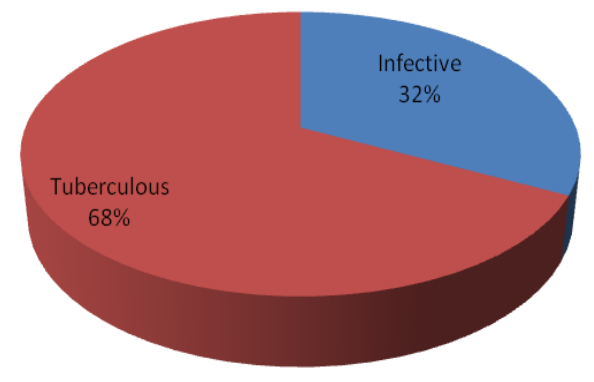

Table 5 Histopathology Diagnosis of Lymphnode

\begin{tabular}{|l|c|c|}
\hline Diagnosis & Frequency & Percentage \\
\hline Infective & 13 & $32.5 \%$ \\
\hline Tuberculous & 27 & $67.5 \%$ \\
\hline Total & 40 & $100 \%$ \\
\hline
\end{tabular}

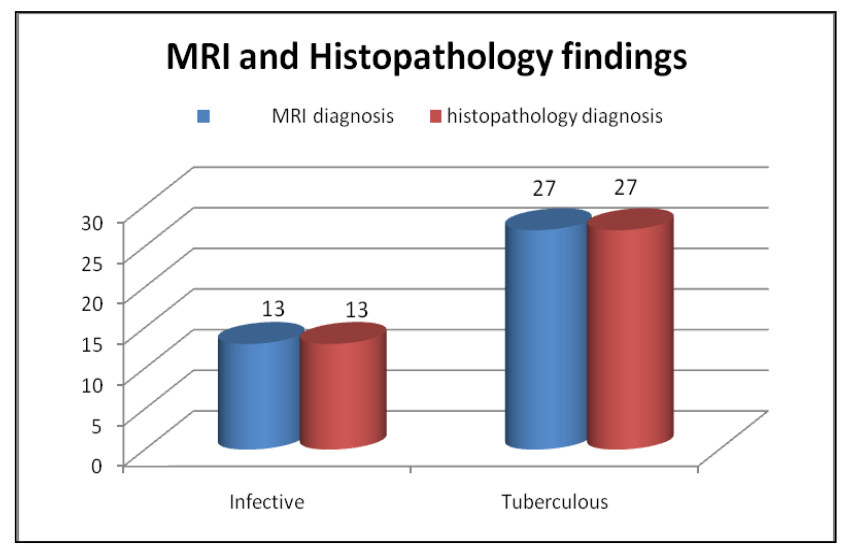

Table 6: MRI Diagnosis with Histopathology Correlation

\begin{tabular}{|l|c|c|}
\hline & $\begin{array}{c}\text { MRI } \\
\text { diagnosis }\end{array}$ & $\begin{array}{c}\text { histopathology } \\
\text { diagnosis }\end{array}$ \\
\hline Infective & 13 & 13 \\
\hline Tuberculous & 27 & 27 \\
\hline Total & 40 & 40 \\
\hline
\end{tabular}

Table 7: Chi-Square Analysis of MRI with Histopathology

\begin{tabular}{|lccc|}
\hline & Value & df & Asymp. Sig. \\
& (2-sided) \\
Pearson Chi-Square & $110.902(a)$ & 4 & .000 \\
Likelihood Ratio & 117.392 & 4 & .000 \\
N of Valid Cases & 40 & & \\
& & & \\
\hline
\end{tabular}

a 3 cells $(33.3 \%)$ have expected count less than 5 . The minimum expected count is 3.08 .

The cross tabulations study showed that there is strong association of MRI with histopathology with a ' $\mathrm{P}$ ' value of 0.00 [ $\mathrm{P}$ value of $<0.05$ strong association]

In the total number of patients studied (40) there was a mismatch in the diagnosis of 1 patient on MRI and histopathology. MRI gave a total of 19 patients as having malignancy (metastatic lymphadenopathy) whereas the actual number of patients having malignancy or metastasis was 18 according to histopathology. This was the grey zone in the diagnosis of MRI where is was not able to diffrentiate between the lymph nodes .

Table 8: ADC in Differentiation of Infective Lymph Nodes

\begin{tabular}{|l|l|l|l|}
\hline $\begin{array}{l}\mathrm{ADC}\left(\times 10^{-}\right. \\
3 \mathrm{~mm} 2 / \mathrm{s}) \\
\text { solid portion }\end{array}$ & $\begin{array}{l}\mathrm{ADC}\left(\times 10^{-}\right. \\
3 \mathrm{~mm} 2 / \mathrm{s}) \\
\text { necrotic } \\
\text { portion }\end{array}$ & $\begin{array}{l}\text { MRI } \\
\text { diagnosis }\end{array}$ & $\begin{array}{l}\text { Histopatholoic } \\
\text { al diagnosis }\end{array}$ \\
\hline $1.0-1.2$ & No necrosis & $\begin{array}{l}\text { Infective } \\
\text { etiology }\end{array}$ & $\begin{array}{l}\text { Infective } \\
\text { etiology }\end{array}$ \\
\hline
\end{tabular}

Table 9: ADC in Differentiation of Tuberculous Lymph Nodes

\begin{tabular}{|l|l|l|l|}
\hline $\begin{array}{l}\mathrm{ADC}\left(\times 10^{-}\right. \\
3 \mathrm{~mm} 2 / \mathrm{s}) \text { of } \\
\text { solid portion }\end{array}$ & $\begin{array}{l}\mathrm{ADC}\left(\times 10^{-}\right. \\
3 \mathrm{~mm} 2 / \mathrm{s}) \\
\text { necrotic portion }\end{array}$ & $\begin{array}{l}\text { MRI } \\
\text { diagnosi } \\
\mathrm{s}\end{array}$ & $\begin{array}{l}\text { Histopatholoi } \\
\text { cal diagnosis }\end{array}$ \\
\hline $0.99-1.01$ & $1.27-1.31$ & $\mathrm{~TB}$ & $\mathrm{~TB}$ \\
\hline
\end{tabular}

All ADC values were corresponding with the histopathology. We can thus see that MRI [ADC values] is having $100 \%$ sensitivity and $100 \%$ specificity as compared to histopathology, which also showed $100 \%$ sensitivity, and specificity in correctly diagnosing cervical lymph adenopathies. 


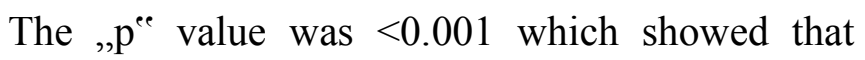
ADC values are highly significant in the differentiation of benign and malignant lymph nodes. This showed that there is good agreement between the ADC values and the histopathology results.

The interpretation of DWI in such a complex area as the head and neck is not straightforward, requiring training and experience. Reproducing these promising results on a broad scale will be a challenge, and technique standardisation is desirable. For example, the results obtained are very dependent on the selection of the $b$-values. Also other technical issues, such as magnetic field inhomogeneity or suboptimal placement of receiver coils, have a strong negative effect on image quality.

All the mentioned studies in literature were giving only one value in the lymph node. They were not differentiating between the solid and necrotic portion. In our study we found that the range of ADC values for benign cervical lymph nodes in the solid and necrotic portion was different as compared to the values seen in the malignant nodes.. The sensitivity was $100 \%$ and the specificity was $100 \%$ and the accuracy was $100 \%$. The ,p pe value was $<0.001$, which showed that the ADC values are highly significant in the differentiation of benign and malignant lymph nodes of neck. The „, Ke value was 0.9 . This showed that there is good agreement between the ADC values and the histopathology results.

Therefore, although most radiologists emphasize that these techniques are very accurate, most clinicians have maintained that none of these techniques is perfect and thus refrain from adjusting their management policy in individual cases according to the outcome of these imaging modalities. Currently there are compelling clinical and pharmaceutical needs to move towards an ideal diagnostic imaging technique able to assess the cancer burden avoiding radiation exposure and to fulfill some essential prerequisites: accuracy, availability, reproducibility, cost effectiveness, and efficiency. DWI seems to fulfill these requirements, because no ionizing radiation is administered and no intravenous injection of isotopes or any contrast medium is necessary.

\section{DISCUSSION}

The objective of the study is to determine the accuracy of MRI [DWI/ADC] in differentiating between benign and malignant enlarged cervical lymph nodes.

In our study we surveyed a total of 40 patients with cervical lymphadenopathy. Of these 40 patients underwent FNAC and were included in the study.

In the 40 patients we have seen, we were able to formulate a range of ADC values within which if the lymph nodes fell we have categorized them as benign or malignant.

The maximum number of patients was seen in the age group of $31-40$ years with maximum age of 81 and a minimum age of 22 years. We found that there was no particular predilection of the nature of the lymphadenopathy to the age of the patient.

Amongst the patients studied, 10 patients had few $(</=10)$ lymph nodes involved $(25 \%)$ and 30 patients had multiple (>10) lymph nodes involvement $(75 \%)$. We tried to find a correlation between the multiplicity of the lymph nodes and the benign or malignant nature of the disease. It was seen thatthe ' $p$ ' value was 0.022 which showed that there was moderately significant correlation.

Amongst the patients studied, 8 had largest lymph node sizes between $1.1-2.0 \mathrm{cms}, 18$ had largest lymph node sizes of $2.1-3.0 \mathrm{cms}$ and 14 had largest lymph node sizes of $>3.1 \mathrm{~cm}$. Mean of largest lymph node sizes of benign lymph nodes was $2.4 \mathrm{cms}$ with a standard deviation of 0.2 , median of largest lymph node sizes of benign lymph nodes was $2.5 \mathrm{cms}$ and range of largest lymph node sizes of benign lymph nodes was 1.9-2.8cms. Mean of largest lymph node sizes of malignant lymph nodes was $2.7 \mathrm{cms}$ with a standard deviation of 0.5 , median of largest lymph node sizes of malignant lymph nodes was $2.8 \mathrm{cms}$ and range of largest lymph node sizes of malignant lymph 
nodes was $1.8-3.6 \mathrm{cms}$. It was seen that there was no particular correlation between the lymph node size and the nature of the lymph node.

In our study we saw that 14 patients had unilateral lymph nodes [35\%] while bilateral lymph nodes were seen in 26 of the patients [65\%]. There was no particular disease predilection for unilatrality or bilatrality of the lymph nodes.

Amongst the total number of cases studied 29 patients had lymph nodes with necrosis [72.5\%] whereas 11 patients had lymph nodes without necrosis [27.5\%].

On ultrasonography amongst the patients studied 29 patients showed signs of necrosis $(72.5 \%)$ and no necrosis was seen in 16 patients $(27.5 \%)$. Of the 29 lymph nodes with necrosis MRI showed lower ADC values.

Bondt et al. ${ }^{[8]}$ reported that the ADC values of malignant cervical lymph nodes were significantly lower compared with benign cervical lymph nodes with mean values of $0.85 \times 10-3 \mathrm{~mm} 2 / \mathrm{s}$ and $1.2 \times 10-3 \mathrm{~mm} 2 / \mathrm{s}$ respectively. He also stated that the optimal ADC threshold value for the diagnosis of malignant cervical lymph nodes was $1.0 \times 10-3 \mathrm{~mm} 2 / \mathrm{s}$ with sensitivity, specificity, positive predictive value (PPV) and negative predictive value (NPV) of 92.3\%, 83.9\%,43.6\% and $98.8 \%$ respectively.

Our study showed similar correlation where the mean ADC values seen in malignant cervical lymph nodes were $0.87 \times 10-3 \mathrm{~mm} 2 / \mathrm{s}$ and in benign cervical lymph nodes were $1.27 \mathrm{x}$ $10-3 \mathrm{~mm} 2 / \mathrm{s}$.

Amongst all the cases MRI showed higher ADC values in 40 patients with enlarged cervical lymphadenopathy which were proven to be benign in nature. In our study the mean ADC value in benign cervical lymphadenopathy was 1.27 x 10-3 $\mathrm{mm} 2 / \mathrm{s}$

Perrone et al. showed that the mean ADC value of benign lymph nodes was $1.44 \times 10-3 \mathrm{~mm} 2 / \mathrm{s}$ and of malignant (metastatic ) cervical lymph nodes was $0.85 \times 10-3 \mathrm{~mm} 2 / \mathrm{s} 1$. He thus concluded that the ADC value of benign cervical lymph nodes was higher than those of malignant. The best threshold value for differentiating malignant from benign nodes was $1.03 \times 10-3 \mathrm{~mm} 2 / \mathrm{s}$ obtaining a sensitivity of $100 \%$ and a specificity of $92.9 \%$.

Our study showed similar correlation with the above study, wherein the ADC values for benign lymph nodes was high

As there was no incidence of necrosis in infective lymph nodes only a single value was taken. ADC mapping showed that the lymphnodes whose values were between 1.0 and 1.2 were found to be of infective nature on histopathology.

Chang et al.reported an ADC threshold value of $1.22 \times 10-3 \mathrm{~mm} 2 / \mathrm{s}$, with a sensitivity of $91 \%$ and a specificity of $93 \%$ for differentiation of benign and malignant lymph nodes of neck. Our study showed similar correlation with the above study, wherein the ADC values for benign lymph nodes was comparatively higher than for malignant lymph nodes.

Sumi et al. reported that the ADC was significantly greater in metastatic cervical lymph nodes $((0.410+/-0.105) \times 10-3 \mathrm{~mm} 2 / \mathrm{s})$ than in benign cervical lymph nodes $((0.302+/-$ $0.062) \times 10-3 \mathrm{~mm} 2 / \mathrm{s})$. Lymphomas showed even lower levels of ADC $((0.223+/-0.056) \times 10-3$ $\mathrm{mm} 2 / \mathrm{s})$. This may be because $48 \%$ of their metastatic cervical lymph nodes had central necrosis resulting in a large variability in the ADC values of these nodes.

Sumi et al. found that the ADC of metastatic cervical lymph nodes $(1.167+/-0.447) \times 10-3 \mathrm{~mm} 2)$ was significantly higher than that of benign cervical lymph nodes $((0.652+/-0.101) \times 10-3 \mathrm{~mm} 2$ $/ s)$ and that of lymphomas $((0.601+/-0.427) \times 10$ $3 \mathrm{~mm} 2 / \mathrm{s})$. The ADC of lymphomas was significantly lower than that of the benign cervical nodes. They might have found higher ADC values in metastatic cervical lymph nodes since they did not analyze necrotic and solid parts of lymph nodes separately. ADC values measured in necrotic areas were high in Holzapfel et al. study $(1.98 \times 10-3 \mathrm{~mm} 2 / \mathrm{s})$ and in Razek et al..study $(1.96 \times 10-3 \mathrm{~mm} 2 / \mathrm{s})$.

Tamer F. Taha Ali et al reported in his study that the mean ADC values of benign, metastatic and 
lymphomatous neck nodes were $(1.51+/ 0.36) \times$ $10-3 \mathrm{~mm} 2 / \mathrm{s}, \quad(0.92+/-0.13) \times 10-3 \mathrm{~mm} 2 / \mathrm{s} \quad$ and $(0.74+/-0.14) \times 10-3 \mathrm{~mm} 2 / \mathrm{s}$ respectively. The ADC values of the benign neck lymph nodes were significantly higher than those of metastatic nodes and lymphoma. Furthermore, the ADC values of the metastatic neck lymph nodes were significantly higher than those of lymphoma. The best ADC threshold value for differentiating benign and malignant lymph nodes was $1.15 \times 10-3 \mathrm{~mm} 2 / \mathrm{s}$ with sensitivity, specificity, positive predictive value (PPV), negative predictive value (NPV), ,p $\mathrm{p}^{\text {"e }}$ value and „, $\mathrm{K}^{\text {ee }}$ value 96\%, 88.9\%, 96\%, 88.9\%, 0.84 and $<0.0001$ respectively.

Two values were taken in each lymph node. One from the necrotic portion and one from the solid portion of the lymph node. On MRI/ADC mapping, lymph nodes whose values were between $0.99-1.01$ in the solid portion and 1.27 1.31 in the necrotic portion were given a diagnosis of tuberculous lymphadenitis. This corresponded to a total of 27 patients who were also given a diagnosis of TB lymphadenitis / granulomatous lymphadenitis on histopathology. Thus MRI showed $100 \%$ correlation with histopathology in diagnosing tuberculous lymphadenopathy.

Holzapfel et al. in their study found that the mean ADC value of malignant (metastatic and lymphomatous) cervical lymph nodes was $(0.74+/ 0.11) \times$ $10-3 \mathrm{~mm} 2 / \mathrm{s}$. ADC values of metastaic lymph nodes ranged between $0.62 \times 10-3 \mathrm{~mm} 2 / \mathrm{s}$ and $0.93 \times 10-3 \mathrm{~mm} 2 / \mathrm{s}$ with a mean $\mathrm{ADC}$ value of $(0.78+/ 0.09) \times 10-3 \mathrm{~mm} 2 / \mathrm{s}$. ADC values of lymphomatous nodes ranged between $0.51 \times 10-3 \mathrm{~mm} 2 / \mathrm{s}$ and $0.76 \times 10-3 \mathrm{~mm} 2 / \mathrm{s}$ with a mean ADC value of $(0.64+/ 0.09) \times 10-3 \mathrm{~mm} 2 / \mathrm{s}$. ADC values of benign lymph nodes ranged between $0.84 \times 10-3 \mathrm{~mm} 2 / \mathrm{s}$ and $1.47 \times 10-3 \mathrm{~mm} 2 / \mathrm{s}$ with a mean ADC value of $(1.24+/ 0.16) \times$ $10-3 \mathrm{~mm} 2 / \mathrm{s}$. The optimal threshold ADC value for differentiating between benign and malignant cervical lymph nodes determined by receiver operating characteristic (ROC) curve analysis was $1.02 \times 10-3 \mathrm{~mm} 2 / \mathrm{s}$ which resulted in a sensitivity of $100 \%$, a specificity of $87.0 \%$, an accuracy of $94.3 \%$, a positive predictive value (PPV) of $90.9 \%$ and a negative predictive value (NPV) of $100 \%$.

Barchetti et al. found that in the 412 histologically confirmed benign lymph nodes of neck the mean ADC value was $1.650 \times 10-3 \mathrm{~mm} 2 / \mathrm{s}$ (range: $0.945-2.370 \times 10-3 \mathrm{~mm} 2 / \mathrm{s})$ and in the 239 histologically proven metastatic lymph nodes of neck the mean ADC value was $0.903 \times 10-3 \mathrm{~mm} 2 / \mathrm{s}$ (range: $0.400-0.996 \times 10-3 \mathrm{~mm} 2 / \mathrm{s}$ ). The most reliable threshold of ADC value derived from the receiver operating characteristic (ROC) curve analysis for differentiating benign and metastatic lymph nodes of neck was $0.965 \times 10-3 \mathrm{~mm} 2 / \mathrm{s}$ which was showing sensitivity of $97 \%$, specificity of $93 \%$, accuracy of $92 \%$, positive predictive value (PPV) of $95 \%$, and negative predictive value (NPV) of $96 \%$.

Razek et al.reported that the mean ADC value of metastatic $(1.09+/ 0.11 \times 10-3 \mathrm{~mm} 2 / \mathrm{s}) \quad$ and lymphomatous $(0.97+/-0.27 \times 10-3 \mathrm{~mm} 2 / \mathrm{s})$ cervical lymph nodes was significantly lower than that of benign $(1.64+/-0.16 \times 10-3 \mathrm{~mm} 2 / \mathrm{s})$ cervical lymph nodes. When an ADC value of $1.38 \times 10-3 \mathrm{~mm} 2 / \mathrm{s}$ was used as a threshold value for differentiating benign and malignant lymph nodes, the results obtained were a sensitivity of $98 \%$, a specificity of $88 \%$, an accuracy of $96 \%$, a positive predictive value (PPV) of $98.5 \%$ and a negative predictive value (NPV) of $83.7 \%$.

The ADC values were corresponding with the histopathology in all. Thus in our study we saw MRI [ADC values] having $100 \%$ sensitivity and $100 \%$ specificity as compared to histopathology, which also showed $100 \%$ sensitivity, and specificity in correctly diagnosing cervical lymph adenopathies. The ,p ${ }^{\text {ee }}$ value was $<0.001$ which showed that ADC values are highly significant in the differentiation of benign and malignant lymph nodes.

\section{Limitations of the study}

In our study we did not correlate the possibility of necrotic lymph nodes with extracapsular spread, 
which if correlated we could have had more insight into the disease process.

\section{Newer Techniques and possibilities}

Recent advances in iron oxide nanocrystal technology [SPIO and USPIO] along with T1WI and $\mathrm{T} 2 * \mathrm{WI}$ for medical imaging plays an important role for angiography and detection of in vasibility of the tumor/ lymph nodes.

FDG whole body PET/ MRI can be used to detect the spread of the disease.

\section{CONCLUSION}

In our study we found that the range of ADC values for benign cervical lymph nodes was between $0.99-1.03 \times 10-3 \mathrm{~mm} 2 / \mathrm{s}$ in the solid portion of the lymph node and $1.27-1.31 \times 10$ $3 \mathrm{~mm} 2 / \mathrm{s}$ in the necrotic portion of the lymph node. The mean of ADC values for tuberculosis cervical lymph nodes was between $0.99-1.01 \times 10$ $3 \mathrm{~mm} 2 / \mathrm{s}$ in the solid portion and in the necrotic portion the values were ranging from $1.27-1.31$ $\times 10-3 \mathrm{~mm} 2 / \mathrm{s}$. The sensitivity was $100 \%$ and the specificity was $100 \%$ and the accuracy was $100 \%$. The ,p $\mathrm{p}^{\text {ee }}$ value was $<0.001$, this showed that there is good agreement between the ADC values and the histopathology results.

Hence findings of our study and other studies quoted above suggest that the ADC values can well be used in the differentiation of infective and tuberculous lymph nodes of neck.

\section{BIBLIOGRAPHY}

1. Koc „ O, Paksoy Y, Erayman I, Kivrak AS, Arbag H. Role of diffusion weighted MR in the discrimination diagnosis of the cystic and/or necrotic head and neck lesions. Eur J Radiol 2007;62:205-213.

2. Castelijns JA, van den Brekel MW. Imaging of lymphadenopathy in the neck. EurRadiol 2002;12:727-738.

3. King AD, Tse GM, Ahuja AT, et al. Necrosis in metastatic neck nodes: Diagnostic accuracy of CT, MR imaging, and US. Radiology 2004;230:720-726.
4. Van den Brekel MW, Castelijns JA, Snow GB. The size of lymph nodes in the neck on sonograms as a radiologic criteria for metastasis: How reliable is it? AJNR Am J Neuroradiol 1998;19(4):695-700.

5. Van den Brekel MW, Castelijns JA, Snow GB. Detection of lymph node metastases in the neck, radiologic criteria. Radiology 1994;192(3):617618.

6. Curtin HD, Ishwaran H, Mancuso AA, Dalley RW, Caudry DJ, McNeil BJ (1998) Comparison of CT and MR imaging in staging of neck metastases. Radiology 207:123-130.

7. Veit P, Ruehm S, Kuehl H, et al. Lymph node staging with dual-modality PET/CT: Enhancing the diagnostic accuracy in oncology. Eur J Radiol 2006;58:383-389.

8. De Bondt RB, Nelemans PJ, Hofman PA, et al. Detection of lymph node metastases in head and neck cancer: A meta-analysis comparing US, USgFNAC, CT and MR imaging. Eur J Radiol 2007;64:266-272.

9. Le Bihan D, Breton E, Lallemand D, Aubin ML, Vignaud J, Laval-Jeantet M. Separation of diffusion and perfusion in intravoxel incoherent motion MR imaging. Radiology 1988;168:497-505.

10. Herneth AM, Guccione S, Bednarski M. Apparent diffusion coefficient: Aquantitative parameter for in vivo tumor characterization. Eur J Radiol 2003;45:208 -213 .

11. 11.Qizilbash AH, Young JEM, Eds. Lymph nodes. Inguides to Clinical Aspiration Biopsy: Head and Neck. New York: Igaku-Shoin 1988;117203.

12. Hall FG. The functional anatomy of lymph nodes. In Stansfeld AG, DeeArdenne AJ, eds. Lymph Node Biopsy Interpretation. London: Churchill Livingstone, 1992; 328.

13. Castenholz A. Architecture of the lymph node with regard to its function. In Grundmann E, Vollmer E, eds. Reaction Patterns of the Lymph Node. Part 1. Cell 
Types and Functions 1. New York: SpringerVerlag, 1990;1-32.

14. Papadimitriou CS, Kittas CN. Normal structure and function of lymph nodes. In Pangalis GA, Polliack A, eds. Benign and malignant lymphadenopathies. Chur: Harwood Academic Publishers, 1993;113130.

15. Rouvie"re H, Tobias MJ. Anatomy of the human lymphatic system. Ann Arbor (MI): Edwards brothers, inc; 1938. ix,318.

16. Shah JP, et al. Surgical grand rounds. Neck dissection: current status and future possibilities. Clin Bull 1981;11(1):25-33.

17. Robbins KT. Classification of neck dissection: Current concepts and future considerations. OtolaryngolClin North Am 1998;31(4):639-655.

18. Robbins KT, et al. Neck dissection classification update: revisions proposed by the American Head and Neck Society and the American Academy of Otolaryngology-Head and Neck Surgery. Arch Otolaryngol Head Neck Surg 2002;128(7):751-758.

19. Som PM, Curtin HD, Mancuso AA. An imaging-based classification for the cervical nodes designed as an adjunct to recent clinically based nodal classifycations. Arch Otolaryngol Head Neck Surg 1999;125(4):388-396.

20. Robbins KT, et al. Consensus statement on the classification and terminology of neck dissection. Arch Otolaryngol Head Neck Surg 2008;134(5): 536-538.

21. Vincent Chong. Cervical Lymphadenopathy: what radiologists need to know? Cancer imaging (2004) 4; 116-120.

22. Sumi M, Sakihama N, Sumi T, Morikawa M, Uetani $\mathrm{M}$, Kabasawa $\mathrm{H}$ et al.Discrimination of metastatic cervical lymph nodes with diffusion-weighted MR imaging in patients with head and neck cancer. AJNR Am J Neuroradiol. 2003 Sep;24(8):1627-34.
23. Hudgins PA. Contrast enhancement in head and neck imaging. Neuroimaging Clin North Am 1994;4(1):101-115.

24. Shah GV, et al. New directions in head and neck imaging. J SurgOncol 2008;97 (8):644-648.

25. Zima A, et al. Can pretreatment CT perfusion predict response of advanced squamous cell carcinoma of the upper aerodigestive tract treated with induction chemotherapy? AJNR Am J Neuroradiol 2007;28(2):328-334.

26. Bisdas S, et al. Quantitative measurements of perfusion and permeability of oropharyngeal and oral cavity cancer, recurrent disease, and associated lymph nodes using first-pass contrast-enhanced computed tomography studies. Invest Radiol 2007;42(3):172-179.

27. Abdel Razek AA, Gaballa G. Role of perfusion magnetic resonance imaging in cervical lymphadenopathy. J Comput Assist Tomogr 2011;35(1):21-25.

28. Le Bihan D, Turner R. Intravoxel incoherent motion imaging using spin echoes. MagnReson Med 1991;19(2):221-227.

29. Le Bihan D, et al. MR imaging of intravoxel incoherent motions: Application to diffusion and perfusion in neurologic disorders. Radiology1986;161(2):401-417.

30. Turner R, et al. Echo-planar imaging of intravoxel incoherent motion. Radiology 1990;177(2):407-414.

31. Le Bihan DJ, Turner R. Diffusion and perfusion. In: Stark DD, Bradley WG, editors. Magnetic resonance imaging. St. Louis: Mosby; 1992;335.

32. Le Bihan D. Molecular diffusion, tissue microdynamics and microstructure. NMR Biomed 1995;8(7-8):375-386.

33. Herneth AM, Guccione S, Bednarski M. Apparent diffusion coefficient: A quantitative parameter for in vivo tumor characterization. Eur $\mathbf{J}$ Radiol 2003;45(3):208-213. 
34. Lang $P$, et al. Osteogenic sarcoma: Noninvasive in vivo assessment of tumor necrosis with diffusion-weighted MR imaging. Radiology 1998;206(1):227-235.

35. Herneth AM, et al. Vertebral metastases: Assessment with apparent diffusion coefficient. Radiology 2002;225(3):889894.

36. Latour LL, et al. Time-dependent diffusion of water in a biological model system. ProcNatlAcadSci USA 1994;91(4):12291233.

37. Le Bihan D, et al. Diffusion MR imaging: Clinical applications. AJR Am J Roentgenol 1992;159(3):591-599.

38. Le Bihan D, et al. Separation of diffusion and perfusion in intravoxel incoherent motion MR imaging. Radiology 1988;168(2):497-505.

39. Szafer A, et al. Diffusion-weighted imaging in tissues: Theoretical models. NMR Biomed 1995;8(7-8):289-296.

40. Carr H, Purcell E. Effects of diffusion on free precession in nuclear magnetic resonance experiments. Phys Rev 1954;94:630-635.

41. Conturo TE, et al. Diffusion MRI: Precision, accuracy and flow effects. NMR Biomed 1995;8(7-8):307-332. 